\title{
Environmental Education: Role of Physical Environment in Students' Learning in Gilgit-Baltistan, Pakistan
}

\author{
Sultan Alam \\ The Aga Khan University, Institute for Educational Development, \\ Professional Development Centre North (AKUIED-PDCN), Gilgit-Baltistan, Pakistan \\ sultan.alam@aku.edu
}

\begin{abstract}
This study describes an action research report carried out in one of the community-managed schools in Gilgit-Baltistan of Pakistan. The purpose of the study is to explore the effects of the activities to create environmental awareness by paying prime focus on physical environmental conditions. It was observed that school-based smaller activities show a greater change among students, teachers and community members. These include celebration of environmental day, plantation day; quiz competitions, sharing information through notice boards and awareness campaigns to adjacent communities. These smaller activities helped them to realize the importance of environmental education particularly in learning process. The attitudinal change among students, teachers and community members was quite evident. They have shown a natural attachment with the school and its surrounding. Since the success and sustainability of such small-scale interventions are directly associated with active involvement of all the stakeholders of a school community, therefore, the study recommends that this important aspect must be given considerate attention to further augment the natural environment and to maximize the learning processes in schools.
\end{abstract}

Keywords: Environmental Education, Sustainability, Content Knowledge, Students' Learning, Positive Attitude

\section{Introduction}

The drastic changes in the environment has made Environmental Education (EE) as one of the most debatable and appealing themes now days. The main objective of such important education is to develop environmentally-friendly attitudes and behaviors to sustain the life on earth. Palmer (1998) describes the importance of EE as: Environmental education is a process of recognizing values and clarifying concepts in order to develop skills and attitudes necessary to understand and appreciate the interrelationship and interrelatedness among man, his culture and his biophysical surroundings. Environment also entails practice in decision-making and self-formulation of a code of behavior about issues concerning environmental quality (p.7).Traditionally, the prime focus was given to develop knowledge and enhance attitudes assuming that there is a linear relationship between improved environmental knowledge and positive environmental behavior (Darner, 2009). For instance, if individuals acquire environmental knowledge, the end result would be their appropriate behavior. The latest studies in this regard showed that change in environmental behavior is not solely being developed by acquiring improved knowledge (Ajzen, 2002; Ballentyne, Fien, \& Packer, 2000). These propositions invite rethinking towards certain other aspects to facilitate behavior along with environmental knowledge.

The debate about EE within general masses has been a continuous practice in various electronic and print media. Today newspapers, bulletins, and other media are doing their best to create awareness among masses. But the most important individuals, students reside in schools need greater focus in this regard. Though EE has been integrated in various syllabi, specifically the science and social studies but this content does not fully equip the students to acquire environmental behavior. As Bashiruddin (2002) found out that teachers find it challenging to teach environmental concepts as they were taught. Similarly, the teachers are assigned subjects without seeking their expertise and interests, so the weaker environmental attitudes of teachers and students could not meet the objectives of adding EE in various syllabi. Highlighting the implications for teachers, Alam (2012) studies suggest that success of various initiatives are achieved when the principal applies participatory approach and assigns the tasks to teachers after their willingness to participate in different activities. My long-lasting experiences in schools show that various reasons cause underachievement of the objectives pertaining to environmental education. Some of the major causes include the teachers lacking content-based understanding about EE, the limited practices of environmental concepts' integration with real world and the teachers limited relevant professional expertise to relate knowledge with their surroundings. 
The important role of EE in curriculum has been described widely, but there seems a general consensus that it impacts on attitudes and ultimately behaviors. In this connection, Clayton and Myers (2009) utter that environmental education seeks to affect worldviews, attitude, and behavior. So, a curriculum with new approaches towards EE can create a successful educational programs for both teachers and students, ultimately beneficial for maintaining a beautiful environment and sustainable future. In school curriculum, the EE provides the platform for the students to know about their environment and develop certain skills to resolve environmental issues in their surroundings. The most important aspect of such learning is developing attitudes towards the care and aptitudes to protect it from external factors which cause deterioration to naturally-built environment. Here the role of teachers becomes very vital as they are the leading bodies to develop certain strategies and design activities to foster students' knowledge and aptitudes. In view of Deemer (2004) teachers' beliefs and perceptions are crucial to develop such attitudes. Besides content knowledge regarding EE, the role of physical environment plays a vital role in developing learning aptitudes among students. This may include the inside and outside physical conditions including attractive arrangements of various items, the cleanliness, the attractive walls and other units reflecting inviting atmosphere for the learners. The research studies by Berry (2002) showed improvements in attitude among all users after a school was physically improved. It was pointed out that the physical changes to the environment contribute to the overall learning environment experienced by everybody.

The Gilgit-Baltistan context of Pakistan depicts out the similar picture and practices regarding EE, practiced in overall curricular practices in Pakistan. The EE does not seem to be a separate subject just like Science, Mathematics or any other language subjects. Various environmentally-related themes have been added in different subjects particularly in Science and Social Studies subjects. The content in the primary level is very thin compared to upper level subjects. Ironically, being integrated subject matter; little effort is being made by the teachers to integrate the content with the real physical world. A knowledge-driven approach is being applied to create awareness, knowledge and skills among the students in the field. There is dire need of the context to pay serious attention towards revisiting the old practices within schools, teachers and overall general mass about their effective roles in maintaining the environment. This can be achieved if the teachers and students are equipped with EE through various applicable activities. There is need to pay special concentration towards improving the physical structure and improved teaching practices in line with the modern approaches. To address the highlighted gaps, this study intends to create environmental awareness and improvements in physical conditions within schools and communities to meet the objectives of improved learning and environmental sustainability. For that an action research approach has been carried out in a three-tiered cyclic approach. The first cycle was based on facilitating the teachers to analyze the curriculum and improve their content knowledge. In the second cycle, the physical environment of the school was focused with deeper involvement of the students. During the third cycle, community awareness campaigns were carried out to sustain the physical structure of the environment within communities reside around the school premises.

Purpose and Research Questions: The purpose of the research study is to enhance the students learning by paying special focus on improving the physical structure of the school. Hence the study was guided by the following main and subsidiary questions:

Main Question: How the physical environment of the school play its' role in improving the learning outcomes of the students?

\section{Subsidiary Questions}

- How classroom physical environment contribute to students' learning?

- In what ways the teachers environmental content knowledge affect students' learning?

- What is the effect of external school environment in students' learning?

- In what ways the beautification inside school premises motivates students towards learning processes? 


\section{Literature Review}

Various connotations have been widely used in the literature pertaining to environmental awareness and sustained learning. Some of the research studies highlight physical environment of the schools as important aspect in learning processes but there are few other thoughts which advocate the content and teachers competencies to improve students' learning. There seemed a general consensus that Environmental Education for Sustainable Development (EESD) is emerging as an essential tool to change student's commitment, motivation, stewardship, behavior and attitudes (UNESCO, 2011).Certain propositions consider teachers' role as prime progression for improved learning. Advocating the role of teachers in developing environmental education and improved learning among the students, Fink (2003) pointed out that the traditional classroom lecture-based teaching learning approach have limited effectiveness in helping students to retain information, become self-learners, and develop skills in transferring knowledge and solving problems. He is of the view that lecture method seemed ineffective in developing the skills among learners as it did not provide enough practical opportunities for the students to relate the content with the actual situation of the environment. There is dire need that experiential learning approach is applied to inculcate scientific outlook food behavior, positive social and environmental attitudes (Blair, 2009). Experiential learning in the natural areas enhancing students' meta-cognitive abilities, their capacity to apply newly acquired skills and knowledge to real-life situations, and the ability to become self-directed learners (Kolb \& Kolb, 2006).

Referring towards alternative teaching approaches, Sarkar \& Frazier (2008) suggest play-based approaches to teach environmental education. They utter that such teaching approach in EE provides students with numerous opportunities for learning in real situations. Applying the play-based approaches and their outcomes within classrooms, Mackenzie and Edwards (2013) emphasized that play-based teaching approaches in education must be integrated into environmental education. Drama, one of the important playbased approaches particularly among middle school students aged 12 to 14 , is one of the inviting strategies to develop students' understanding of basic environmental and ecological concepts (Whitty, 2006; Stone, 1989).There are other school of thoughts providing additional dimensions of teaching approaches and their impact on students' learning. In this regard, Deemer (2004) considered the teachers aptitudes as important ingredient, saying that teachers' beliefs and perceptions are crucial showing direct impact on students' learning. There are some other factors which could affect the beliefs of the teachers. In one of the research studies, Cooper (1985) asked primary school teachers about their school buildings and argues that 'whether physical environments are themselves capable of disabling education, teachers' belief in their capacity to do so could prove self-fulfilling. For it could act to lower their morale and motivation, so eroding their commitment to teaching" (p.267). In later studies, he proposed that the teachers and staff morale needs to be of key importance to enhance teaching commitment among teachers (Cooper, 2000). Similar results were also gathered by Berry (2002) that improvement in physical structure is directly linked with the improvements in attitude among all users in schools. Such improvements can be seen as resulting from the physical changes to the environment which then contributes to the overall learning environment experienced by everybody.

The literature advocates physical structure as another dimension, considering its important role in improving the learning outcomes of the students. Horne-Martin (2002) studied the role of classroom in developing learning aptitudes among students and found that the style of teaching and room organization are linked with each other. Here, the studies conducted by Ahrentzen and Evans (1984) confirmed that more open classrooms do have some direct effect on how teachers teach. Canter and Donald (1987) also endorse the role of physical element but they add another element as educational philosophy presenting that "the essential element was the school's educational philosophy and physical layout, not merely the physical layout on its own" (p.1292). There are other studies highlight the inner arrangements of classrooms as imperative features for improved learning. They mainly focus on seating arrangements, lighting and color of the classroom insides. For instance, Earthman (2004) rates temperature, heating and air quality as the most important individual elements for student achievement. Knez (1995) found evidence that lighting conditions induce negative effect, reduce performance, and concluded that improved lighting conditions develop positive affect by improving learners' performance. While assessing the needs of classrooms in US states' schools, two studies (Young et al, 2003; Buckley et al, 2004) also demonstrate the importance of these issues in students' 
learning processes. Similarly, Fisher (2001) endorses such propositions considering their role in affecting students' behavior and outcomes.

Khattar et al, (2003) consider ventilation within classrooms as important ingredient to maximize learning processes. The indoor air is directly linked with students' health (Ahman et al, 2000). In this connection, Smedje and Norback (2001) argue that since irritants and allergens collect in dust, it might be advisable to avoid particular sorts of 'fleecy' furnishings and open shelving and to increase the frequency of cleaning. Rosen and Richardson (1999) went further by linking poor air quality to absenteeism. They found that reducing the number of particles in the air, and so improving air quality, in a schools particularly in nursery classes resulted in reduced child absence. They concluded that air quality has serious implications for learning and academic achievement. The overall literature presents various forms of environment and its impact on students' learning outcomes. It seems that various factors within and outside school environment contribute towards learning processes. An analysis of the literature perspectives show that the physical environment of the school has a direct relation with the students learning. It is important to consider the improved physical improvement to improve ultimate learners' academic performance. Such improvements can be brought in and around the school by creating an inviting atmosphere. If schools pay their concentration on improving the physical conditions of the school, the overall objectives of the improving students' learning outcomes can be further improved.

\section{Methodology}

Reconnaissance: Before assessing the real situation of the school, a general plan was developed. The plan considered improving the physical conditions, teacher content knowledge and involvement of students to maintain improved environmental conditions assuming that these conditions need paying concentration. Based upon the general plan, the assessment of the school and formal meetings with principal and teachers were carried out to explore the real situation. It was found that the general plan was quite matched with the real situations; hence various activities in the general plan were adjusted in various cycles to implement the planned activities effectively.

Research Design: The study focused on improving the physical conditions of the school and its' effect on students' learning. Therefore, it was important for the researcher to be part of implementation team. Hence, action research under qualitative research paradigm seemed more applicable approach as such approach is being carried out to improve the rationality and justice for practices, understanding of practices and the situation in which practices are carried out (Elliot, 1992). Under these thoughts, the whole research process was carried out in six months in three cycles. More specifically, the study applied the action research after Elliott (cited in Hopkins, 1985) model is given below. Semi-structure interviews from the school principal and selective teachers were conducted to gather the data. This tool allowed the researcher to get feelings and opinions (Hitchcock \& Huges, 1995) of the participants who were directly involved in the implementation stages. Additionally, personal observations, which took place at the research site and important information about the "social setting" (Robson, 1998) were also documented throughout the research process. The researcher also maintained a reflective journal to analyze the successes of planned activities. This helped in personal thoughts and insights about an action, response, event, issue, personal feelings, opinion about a social setting and learning (Kember, 2000).

Data Analysis: Glesne (1998) posits that analyzing the data must continue simultaneously with the gathered data to focus and shape the study as it proceeds. Considering this guideline, analysis of data continued once the data was gathered. This process was carried out in an organized way. For instance, after data collection, it was read thoroughly, summaries were developed and key ideas developed. These ideas were further grouped into similar categories which were further interpreted into cycle-wise research findings under the theme, "The story of my action research". 


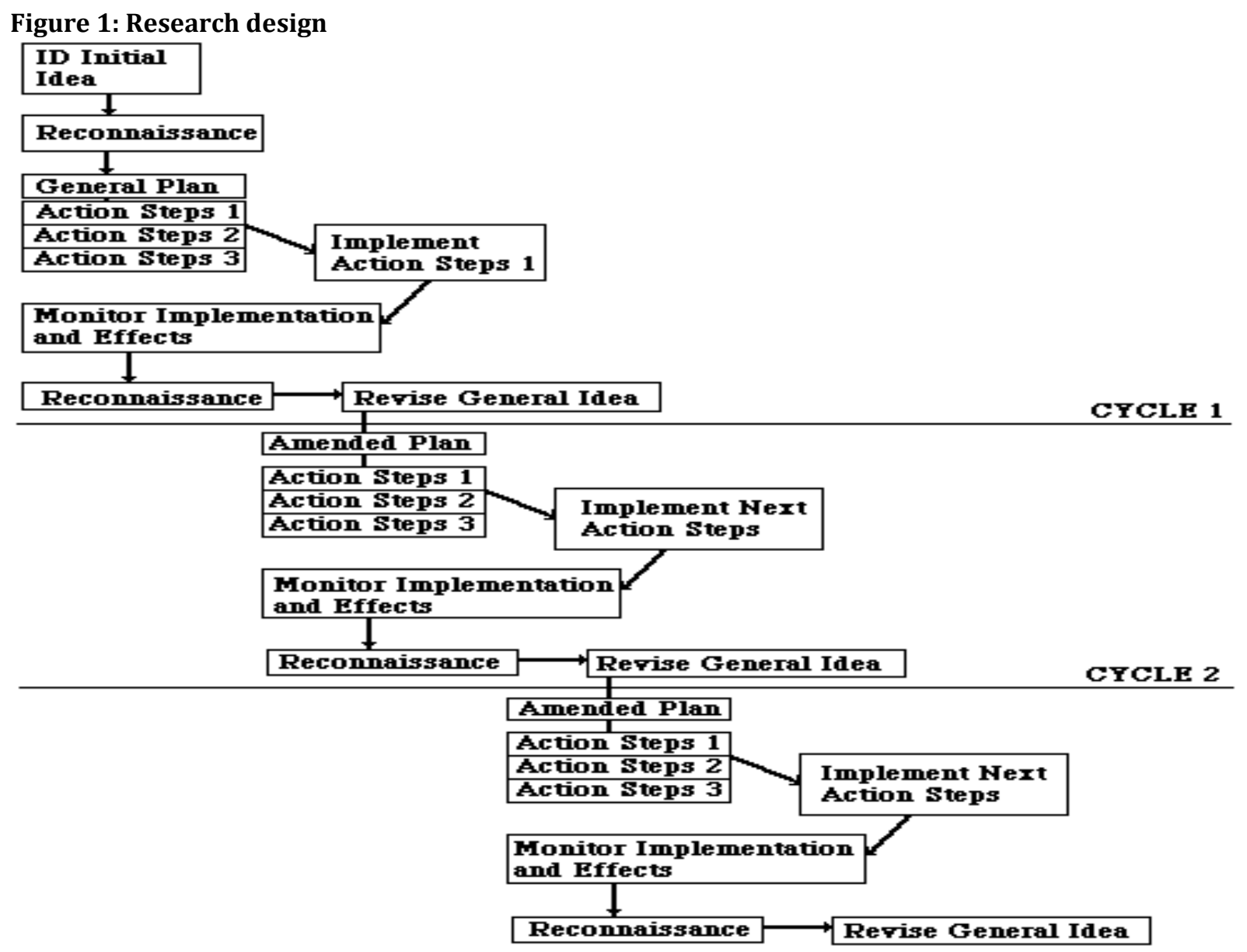

Context of the Study and Selection of Participant: The study was carried out in one of the communitybased secondary schools in Gilgit ${ }^{1}$ town. The school offers co-education to 450 students. This research involved principal, teachers and students' representatives from grade 6-10. A pre-determined criteria was developed to select appropriate school as:

- It must have increased number of students

- It is functioning around densely populated area

- The staff show their willingness to participate in the study

- The principal and teacher will support the pre-determined action plan

Based upon the given criteria, pre-entry negotiations were carried out with the Board of Governors (BoGs). These negotiations were followed by three meetings with the principal and teachers. The focus was paid to inform about the nature of research study, their roles in whole research processes and creating motivation towards proposed study.

Ethical Considerations: Being a professional working under a prestigious university, the prime responsibility was to pay higher concentration to maintain research ethics. For that ethical codes and policies governing interactions with research participants and the collection of data (Glesne, 2006) was strictly maintained. For instance, the research participants were informed about the purpose of the study, its nature and the interval of the whole research study. Additionally, their volunteer involvement was ensured by providing greater freedom to discontinue their participation at any stages. The school name and participants identity was kept confidential by using pseudonyms where applicable.

\footnotetext{
${ }^{1}$ Gilgit town is the capital of district Gilgit and administrative headquarter of Gilgit-Baltistan province.
} 
Limitations of the Study: Just like many qualitative studies, this study was not limitation-free. First, the study being qualitative action research approach limits the generalizability of the findings. Secondly, these findings may not be truly applicable to other schools in the context due to varied contextual conditions.

\section{Results}

Cycle One and its Outcomes: This cycle was carried out in two months period and focused on three of the planned following activities:

- Conducting teachers' workshops

- Reducing water pollution (lectures to classes/demonstrations)

- Cleanliness of the school (inside and surroundings)

- Creating environmental club by involving few students from higher classes

- Sharing information regarding Environmental Education

The formal observations and informal discussions with the teachers and principal revealed that the first activity in this cycle was highly motivating for the teachers. My personal observations within classrooms showed that teachers have improved their content knowledge and developed understanding towards environmental issues prevailing in their context. They have been trying to integrate various environment themes to their context and designed certain smaller activities to convey the message of environmental education. One of the teachers shared her experiences:

Before the session I did not pay special attention towards this important theme. This theme is very much relevant to our area. Now I am sensitized and worried if we did not pay attention towards our beautiful areas, if we will through garbage continuously, one day we will lose our natural beauty. Now, besides teaching environmental themes, I also take few minutes to create more awareness about environment in my classes. (Teacher one Interview)

The outcomes of teachers' workshops were also seen through improved their content knowledge. Generally, being an integrated subject, teachers lack knowledge and understanding regarding environment education. This ultimately showed a lacking knowledge among students about the subject matter. Hence, the teacher's workshop not only served a tool to boost environmental content knowledge within teachers but it also remain fruitful for the entire students as, based upon the gained learning during two workshops, teachers modified their lessons. It was quite evident through classroom observations and demonstrations by the students. During a visit to grade 9, few of the questions were asked about the increasing temperature and its causes, the students were trying to link it with the environmental issues. (Reflective Journal)

The second activity focused on cleanliness of the school and surrounding, and the role of personal hygiene to maintain a healthy atmosphere and body. This activity involved students from grade 6 to 10. For that various areas from within and outside the school were allocated for each grades under the supervision of their class teachers. It was observed that the students involved in the activity with full of zeal and zest. They collected the garbage, dumped in the allocated areas, and cleaned their classrooms. The students from grade 10 cleaned the surroundings of the school. During the next day assembly proceedings, lectures were given by the principal and the researcher to highlight the importance of personal hygiene to develop a healthy body and effects of unprocessed garbage in their learning processes. It was observed that the students followed the given instructions and applying the gained learning to maintain personal hygiene and reverted the practices of throwing garbage here and there. During school visits, few of the informal questions were asked from selective students regarding cleanliness. It was depicted out that the students were using precautionary measures to maintain their personal hygiene. (Classroom Observation 2)

The classroom visits to highlight the importance of safe water seemed to have a positive impact on students' aptitudes. During the visits, special concentration was made to inform the students about how water is being made clean. The main focus was given on boiling of water up to a certain temperature to make it germ free. To assess the outcomes of this activity, few of the sample students were selected to explore how they make water clean for drinking purposes. One of the students responded that: My mother do water clean for all my family members. Responding towards the process of cleaning water, he told that his father has bought a big 
pot where her mother puts lot of water. She boils it for longer time when it becomes cool; she puts it in water cooler. I bring that water to my school (Student's Interview).

This activity in the first cycle focused on sustaining the environmental awareness and learning activities. For that a school-wide environmental club was made through consultation with the principal and teachers. A team of ten members, two from each classes from grades 6-10 were nominated in this club under the direct supervision of grade 10 class teacher. A formal meeting was arranged with club members and their predefined roles were shared to maintain the healthy physical environment in and around the school. This activity brought a visible change in the school and it was observed that this committee was functioning according to the set objectives. The overall, school environment was improving day by day, and the students were affectionate in attending their school regularly. After one month of this intervention, the supervisor teacher was asked to share her learning during the one month period. Her remarks were quite encouraging, she shared that:

I am highly impressed the way students pay their concentration to maintain the beauty of the school. I observed that the club members regularly visit to all the classrooms, see the cleanliness inside and outside the classrooms. They also guide their fellows and lower classes to make their classes clean. I see that this has greatly affected the students, and the come to school with smiling faces. (Supervisor Teacher Interview)

A reflective session with the principal were quite matched with supervisor's expressions. He uttered that due to maintaining the physical environment of the school, the absenteeism ratio has been dropped drastically. He added that in the earlier month, when he was observing attendance record, 15-20 students remain absent in single days. Now this ratio has dropped down and currently 4-5 students, on average remain absent. The last activity in the first cycle was based upon sharing information about environmental education. For that the teachers and students were encouraged to search the literature and share the news to all the students through notice board. This activity was highly motivating for the students and teachers as well. The dailybased observations showed that at routine basis, they were remain in search of getting new information regarding environmental education and continuously updating the notice board. Hence, this activity remained productive in added new knowledge about environment education within school and ultimately parents and other surrounded communities.

Cycle Two and its Outcomes: The second cycle also spread over two months. After involving the school in general awareness activities about environmental education, this phase focused on certain initiatives within school premises to sustain the efforts and creating a welcoming environment for the learners. More specifically, the following activities were carried out during this phase:

- Celebrating plantation days

- Planting a class garden

- Recycling process (by creating a site for collection of recyclable items)

- Arranging a small site for composting

- Improving physical conditions of classrooms

Through consultation with the school principal and environmental club members, two days were allocated for the plantation days' celebration and planting a class garden. For that various proportions of the school garden and playground were allotted to each class to improve the physical structure with planting new plants. They were encouraged to bring their home-based plants. The researcher also enhanced the motivation of the students by being deeply involved in the activity and bringing certain non-indigenized plants. This activity involved the teachers and students deeply into the activity. A competitive atmosphere was developed as each class tried their best to revamp their allotted area differently. It was observed that each student actively participated in the 2-day activity. They showed keenness towards improving the physical conditions within the school premises. Their deeper involvement in the activity, besides adding towards beauty of the school motivated towards natural resources conservation too. Refereeing towards success of this activity one of the class teachers responded that, "we have been celebrating this event every year but this year remained very special as the students worked in a competitive environment. This approach motivated students and the results are quite evident" (Class teacher interview). 
My deeper reflections also show eye-catching pictures towards the 2-day activities. It reflects that providing motivational tools boost inner feelings of the students. They show sense of belongingness towards motivational tasks and apply their best to produce greater outcomes. The subsequent observations in this regard depicted out that students pay greater care to maintain the beauty of their class gardens by removing any garbage and watering the plants timely. Additionally, similar activities remain fruitful in searching the nature, the concept of ecosystem and searching for applicable solutions to maintain the natural balance. The next activities were based upon creating understanding about the recycling and non-recycling objects in and around the school. Based upon the initial sessions with the teachers, the focus was given to involve the students in practical situations regarding various items. For that the science and social studies teachers were guided to develop the conceptual understanding regards both the concepts. The teachers improved students' understanding through demonstrations as well. The next day, the researcher presented the activity during the assembly proceedings to reiterate the previous activity carried out by the teachers. Additionally, four of the bigger containers were bought and tags were mentioned namely recycling items and non-recycling items. These containers were fixed in four different corners of the school boundaries. The students were asked to put both of the items in their respective containers.

The activity was inspirational for the students as the students developed their understanding regarding recyclable and non-recyclable items. Their engagement in this task was closely monitored, and it was found that students showing an improved practice towards using the containers by putting the items in both the containers. Such practice gradually improved the beauty of the school and by re-using the items, the teachers also developed low-cost and no-cost items, integrated them in their lesson plans and ultimately improved the learning outcomes of the students. A composting area was located at the corner of school playground. For that a smaller ditch was created to put the non-recyclable material and compost them. The watchman was provided with special instructions to empty the containers after school hours. Initially, few of the challenges were observed in applying this practice, but gradually the practice showed improved results and after two weeks, an in-built culture was developed within school and every students and teachers became habitual of this practice. This resulted in creation of an inviting atmosphere within the school and added towards learning opportunities for the students.

The last activity in the second cycle was based upon improving the physical conditions of the classrooms. For that the teachers, students' representatives and environmental club members were involved to improve the physical structure of the classrooms. This activity was quite inviting for the students as based upon the size of the classrooms the focus was given to amend the seating arrangements of chairs and desks, earlier the chairs and desks were fixed. The teachers were encouraged to routinely change the arrangement according to the nature of the subjects and planned activities. Additionally, special attention was given to re-align the displays inside the classrooms. For that subject areas were defined and respective displays were fixed at the allocated areas. The teachers were further informed to change the displays routinely by adding the latest studentsdriven displays. These activities, especially the changing the seating arrangements was quite inspiring for the students. During the classroom observations, it was found that students show deeper involvement in the activities. Here, the semi-circle arrangement was seen quite productive as it involved students to communicate frequently with each other as well as provide opportunity to improve their social skills. Moreover, the students were highly motivated to develop new displays and eager to show their work by fixing it at the allotted subject-wise display areas.

Cycle Three and its Outcomes: This cycle mainly focused on certain activities related to sustainability of physical environment in and around the school. The following activities were carried out during this 2 -month cycle:

- Designing environmental competitions among various classes

- Involving students in some project works

- Arranging sessions for the parents and communities

- Arranging Environmental Walk

The first activity focused on deepen the understanding of the participants. For that two of the sub-activities were designed through mutual consensus with the principal and teachers; environmental competition and involving project works. The teachers were encouraged to involve their respective classes in developing 
certain projects, based upon the levels and understanding of the students. For instance, students in preprimary levels were involved in drawing various themes while the upper class students developed certain models, simulations, role plays and presentations. To encourage the students and continuing such project in future, two competitive sessions were arranged. The first competition was held for primary sections while the second one involved the upper primary and secondary classes. To further boost the students' motivation, certificates were developed to all the participants while trophies and prizes were allocated to winners.

The overall participation and deeper involvement in the project worked showed that it was one of the most exciting activities being carried out during this research work. Here, the students and teachers pay special concentration to develop beautiful models, collected raw materials from homes, searched the literature and school-based text books and worked keenly to represent their classes. Moreover, the teachers showed their higher concentration towards adding updated content, guided the students to collect appealing data and design attractive models. These activities, besides adding towards the content knowledge enhanced the psychomotor skills of the students as they were being involved in art and craft work too. Pointing towards the success of these activities, the principal uttered:

I see similar activity very first time. We have been arranging sessions on different topic but we observed environmental education competition first time in school history. I was deeply fascinated the way teachers and students were doing their best to win the competition. I saw few parents visiting school and discussing about various items lying at homes. This will create a healthy environment in the school. (Principal Interview) My reflections were quite similar to the experiences shared by school principal. I found that teachers were engaged even in after-school hours to develop attractive models. A mobile working environment was seen around the whole school (Ref. Journal). The teachers were discussing about the environmental education during their break times, and a healthy competitive environment was flourished around the school.

The second activity in the third cycle considered parents and communities as major partners in sustaining the efforts. For that one day was allocated during weekend. A formal invitation was sent to parents through their children and announcements were sent to attend the day-long session. For that an interactive discussion and speeches were arranged to highlight the importance of environmental education in child' learning and parents/communities role in developing an attractive environment. Besides, presentations and interactions by researcher, principal and few teachers, the communities were involved in observing the project work performed by their children. This activity remained highly instrumental in reflecting about the existing inappropriate and unpleasant environmental practices around the school vicinity and inviting them to re-visit such practices. The community members, after observing the students activities and improved physical environment of the school came to realize the importance of managing the physical environment to balance the life. They showed their willingness to spread the message of environmental education within their surroundings and will contribute to revitalize the environment which was being degraded by their practices. Additionally, a mutually-agreed plan was discussed where school and communities can play their separate roles to maintain their surroundings. Later on my frequent visits and observations revealed that the community has owned this practice, for instance, the garbage which was being dumped around their homes has been reduced drastically, and the water channel has rare scratched items. Similarly, the road connected with school also presents an improved outlook day by day and the school' surrounding was totally clear from garbage and other items (dumped earlier).

At the end of the action research cycle an environmental walk was arranged within the communities surrounded to school. This activity was planned to improve the efforts to sustain the action research project. For that the students and boy scouts were involved in development of placards, posters and pictures with written slogans and sayings to spread the messages of environmental education and effective learning. This walk was being highlighted in local newspapers which served as a tool to spread the message to wider communities. This activity sensitized the general public regarding the role of improved environmental conditions to develop students' learning. They came to realize the importance of improving their surrounding physical structure. Their practices showed an improved progression towards maintenance of their surroundings. An overall informal concluding visits in these areas depict out that the activities being carried out during the action research phase produced a profound impact on overall stakeholders, in and outside of the school. (Ref. Journal) 


\section{Conclusion and Discussion}

The analysis of findings revealed that six-month action research to assess the role of physical environment in students' learning seemed important learning episodes for the project school. It remained instrumental in developing learning aptitudes among the teachers and students. The rigorous involvement of students and teachers under various activities showed that the activities have revitalized their aptitudes and they are keen to maintain a balanced environment. For that they showed their deeper involvement to understand environment and integrated themes. For example, the concepts waste management, improving physical structure, water and its pollution and caring about other biodiversity were matched with their contexts, hence improved motivation towards contextual needs. These findings endorsed earlier studies conducted by Louis and Jordan (2012) that the pertinent content knowledge adds to the motivation of learners. The study also produced greater outcomes through improved knowledge, skills and attitudes among the communities regarding the environmental issues pertaining to their local environment. For example, they became more sensitized towards improving the physical conditions of their surroundings. Additionally, various environment-related activities carried out within and outside the classrooms provided with the opportunities for the students to re-visit their practices and beliefs about their surrounding and enhanced their content knowledge (Moore \& Lackney, 1993). These findings further confirmed Fink (2003) studies that the traditional classroom lecture-based teaching learning approach have limited effectiveness in helping students to retain information, become self-learners, and develop skills in transferring knowledge and solving problems.

Providing opportunities to search the content and explore beyond the text create positive image among the learners. The data revealed that involving students in surfing various sources for information create positive attitudes towards environment, ultimately building their capacities towards improved environmental actions. Pooley and Connor (2000) present that similar activities develop better cognitive and emotional skills amongst the students to respond environmental issues more meaningfully. This study showed similar results that when students and teachers were involved in multiple activities to search content, their competencies in the subject areas show improved progression. The study showed that physical environment of the school enhance the students' attitudes towards learning. In particular, a well-balanced classroom, attractive outlook with managed boundary walls, corridors and greenery seemed to have apparent effects on teachers and learners. So, this study seemed consistent with the earlier studies by Berry (2002) that improvement in physical structure is directly linked with the improvements in attitude among all users in schools. Additionally, the seating arrangements inside classrooms showed to have a very positive effect on students' inclination towards learning. It was found that students pay keen interest when their seats are being changed with regard to activities. The students' were also changed according their competency levels, i.e. they were provided with the opportunities to work with different fellows routinely. It was evident that such reforms show improved social skills among the students as they prefer to work with different fellows in multiple tasks in a day. Interestingly, these findings seemed to challenge the previous studies carried out by Millard and Stimpson (1980) saying that a change in seating location (whether the students chose their own seats, or were randomly assigned) did not have a significant effect on enjoyment, interest, inclusion, or motivation.

Based upon the findings of the current study, few suggestions have been proposed. First, this study has focused a single school, there is need to conduct empirical investigations of similar kind to explore the effects of various environmental activities in relation to students learning. Moreover, the study has shown a positive effect on students, teachers and communities regarding their rigorous involvement in the activities pertaining to improve the physical structure of the school. These results can further be improved if such practices are being employed in some of the public and private schools within various contexts of Gilgit-Baltistan. This study also has certain implications for policy makers. The findings of this study may be summarized and can be used to enrich the environmental education content in various syllabi. Additionally, environmental education can be embedded in various training programs for the teachers to convey the meaning of EE to pool of the students, particularly in the Gilgit-Baltistan contexts. For that there is need to upgrade EE through locally-driven and applicable to context approaches. 


\section{References}

Ahman, M. Lundin, A. Musabasic, V. \& Soderman, E. (2000). Improved Health after Intervention in a School with Moisture Problems, Indoor Air, 10 (1) 57-62. Retrieved November 20, 2016 from https://www.ncbi.nlm.nih.gov/pubmed/10842461

Ahrentzen, S. \&Evans, G.W. (1984). Distraction, Privacy and Classroom Design. Environment and Behavior, $16(4), 437-454$.

Ajzen, I. (2002). Residual effects of past on later behavior: Habituation and reasoned action perspectives. Personality and Social Psychology Review, 6(2), 107-122.

Alam, S. (2012). Crafting Leaders for Educational Change: Head teacher's Perspectives about a Tailor-made Professional Development Program. International Journal of Social Science and Education, 2(1), 118.

Ballentyne, R., Fien, J. \& Packer, J. (2000). Program effectiveness in facilitating intergenerational influence in environmental education: lessons from the field. The Journal of Environmental Education, 32(4), 815.

Bashiruddin, A. (2002). Seasons of my learning. In J. Edge (Ed), Constructing professional development (pp.104-115). Britain, Eysham: Information Press.

Berry, M.A. (2002). Healthy School Environment and Enhanced Educational Performance: The case of Charles Young elementary school, Carpet and Rug Institute. Retrieved December 8, 2016 from http://files.eric.ed.gov/fulltext/ED473985.pdf

Blair, D. (2009): The Child in the Garden: An Evaluative Review of the Benefits of School Gardening. The Journal of Environmental Education, 40(2), 15-38.

Buckley, J. Schneider, M. \& Shang, Y. (2004). LAUSD School Facilities and Academic Performance, Retrieved November 17, 2016 from http://www.edfacilities.org

Canter, D. V. and Donald, I. (1987). Environmental Psychology in the United Kingdom, in D. Stokols and I. Altman (Eds) Handbook of Environmental Psychology, Vol. 2, Chichester, Wiley.

Clayton, S. \& Myers, G. (2009). Conservation Psychology. Understanding and promoting human care for nature. Wiley-Blackwell.

Cooper, I. (1985). Teachers' Assessments of Primary School Buildings: the role of the physical environment in education. British Educational Research Journal, 11 (3), 253-269.

Coopers, P.W. (2000). Building Performance: An empirical assessment of the relationship between schools capital investment and pupil performance, Department for Education and Employment. Retrieved $\begin{array}{llll}\text { December } & 15, & \text { from }\end{array}$ http://s3.amazonaws.com/zanran_storage/www.dcsf.gov.uk/ContentPages/82174737.pdf

Darner, R. (2009). Self-determination theory as a guide to fostering environmental motivation. Journal of Experiential Education, 40(2), 39-49.

Deemer, S.A. (2004). Classroom Goal Orientation in High School Classrooms: Revealing links between teacher beliefs and classroom environments. Educational Research, 46(1), 73-90.

Earthman, G.I. (2004). Prioritization of 31 Criteria for School Building Adequacy. Retrieved December 15, 2016 from http://www.aclu-md.org/facilities_report.pdf

Elliot, J. (1992). Action Research for Educational Change. UK: Open University Press.

Fink, S. (2003). Creating Significant Learning Experiences: An Integrated Approach to Designing College Courses. San Francisco, California: Jossey-Bass.

Fisher, K. (2001). Building Better Outcomes: The impact of school infrastructure on student outcomes and behavior, Department of Education, Training and Youth Affairs (Australia). Retrieved December 20, 2016 from http://files.eric.ed.gov/fulltext/ED455672.pdf

Glesne, C. (2006). Becoming qualitative researchers: An introduction (3rd Ed.). Boston, MA: Pearson Education, Inc.

Glesne, C. (1998). Becoming qualitative researchers. New York: Longman.

Hitchcock, G. \& Hughes, D. (1995). Research and the Teacher. (2nd Ed.) London: Routledge.

Hopkins, D. (1985). A teacher's guide to classroom research. Philadelphia: Open University Press.

Horne-Martin, S. (2002). The Classroom Environment and its Effects on the Practice of Teachers. Journal of Environmental Psychology, 22 (2), 139-156.

Kember, D. (2000). Inquiry Strategies for Science and Mathematics Learning. Portland: Northwest Education Laboratory. 
Khattar, M., Shirey, D. \& Raustad, R. (2003). Cool \& Dry - Dual-path approach for a Florida school. Ashrae Journal, 45(5), 58-60.

Knez, I. (1995). Effects of Indoor Lighting on Mood and Cognition. Journal of Environmental Psychology, 15 (1), 39-51.

Kolb, A. Y., \& Kolb, D. A. (2006). Learning styles and learning spaces: A review of interdisciplinary application of experiential learning in higher education. In R. Sims and S. Sims (Eds.), Learning styles and learning: A key to meeting the accountability demands in education. Hauppauge, NY: Nova.

Louis, N. \& Jordan, J. R. (2012). Student Attitudes Toward and Recall of Outside Day: An Environmental Science Field Trip. Journal of Educational Research, 105(3), 220-231.

Mackenzie, C., \& Edwards, S. (2013). Pedagogical play-types: what do they suggest for learning about sustainability in early childhood education? International Journal of Early Childhood, 43(3), 327-346.

Marcinkowskit, T. (1991). The Relationship Between Environmental Literacy and Responsible Environmental Behavior in Environmental Education (in) MALDAGUE, M (ed) Methods and Techniques for Evaluating Environmental Education Paris: UNESCO.

Millard, R. J., \&Stimpson, D. V. (1980). Enjoyment and productivity as a function of classroom seating location. Perceptual and Motor Skills. Portland: Northwest Education Laboratory.

Moore, G.T. \& Lackney, J.A. (1993). School Design: Crisis, educational performance and design applications, Children's Environments, 10 (2), 99-112.

Palmer, J.A. (1998). Environmental education in the 21 century: Theory, practice, progress and promise. London: Routledge.

Pooley, J.A. \& Connor, M. O. (2000). Environmental Education and Attitudes: Emotions and Beliefs are what is needed. Environment and Behavior, 32 (5), 711-723.

Robson, C. (1998). Real World Research. Oxford and Cambridge: Blackwell Publishers.

Rosen, K, G. \&Richardson, G. (1999). Would Removing Indoor Air Particulates in Children's Environments Reduce the Rate of Absenteeism? A hypothesis. The Science of the Total Environment, 234 (1), 87-93.

Sarkar, S.\& Frazier, R. (2008). Place-based investigations and authentic inquiry. Science Teacher, 75(2), 2933.

Smedje, G. \&Norback, D. (2001). Irritants and Allergens at School in Relation to Furnishings and Cleaning, Indoor Air, 11(2), 127-133.

Stone, C. A. (1989). Improving the Effectiveness of Strategy Training for Learning Disabled Students. The role of Communicational Dynamics. Remedial and Special Education, 10(1), 35-42.

Whitty, G. (2006). Teacher Professionalism in a new era. Retrieved April 5, 2016 from http://www.gtcni.org.uk/publications/uploads/document/annual\%20lecture\%20paper.pdf.

Young, E., Green, H. A., Roehrich-Patrick, L., Joseph, L. \&Gibson, T. (2003). Do K-12 School Facilities Affect Education Outcomes? The Tennessee Advisory Commission on Intergovernmental Relations. 